\author{
K. Morita*, T. Suzuki*, T. Taketsuru*, D. G. Evans**, W. Yang** \\ * Daido Steel Co., Ltd., Nagoya, Japan \\ ** Special Metals Corporation, New Hartford, NY
}

\begin{abstract}
Solidification macro-segregation, particularly in the form of freckles, in nickel base superalloys is the main cause for the limitation of the ingot diameter and melting rate during vacuum arc remelting (VAR) and electro-slag remelting (ESR) process.

The critical solidification conditions for freckle formation in Alloy 718 were studied by horizontal directional solidification (H-DS) experiments under various solidification conditions, and validated by commercial sized VAR ingots. The tendency for freckle formation in this alloy was evaluated by an expression based on the Rayleigh criterion including solidification rate, thermal gradient in the mushy zone, and solidification front angle to the horizontal plane.

In order to systematize the methods to predict proper VAR operating conditions for any alloy and ingot diameter, a solidification simulation approach has been developed based on the results of the above trials.
\end{abstract}

\title{
Introduction
}

Recently, superalloy producers have been required to produce vacuum arc remelting (VAR) and electro-slag remelting (ESR) ingots, which has larger diameter in some types of alloys, because of the stronger demand than ever for the scale-up of the aircraft engines and land-based gas turbines. However, solidification macro-segregation, particularly in the form of freckles, in the nickel base superalloys is one of the main cause for the limitation of the ingot diameter and melt rate during these processes, and it has not been completely systematized yet.

Freckle is a kind of macro-segregation, which can be seen as liner trails of equiaxed grains with eutectic constituents along the vertical plane around the mid-radius region in remelted ingots, and which is undesirable in any application because of their unremovability by any thermal or mechanical treatments after remelting process. Freckle defects are believed to be generated as a result of thermosolutal convection against the dendrite arm resistance, which is caused by the density inversion in the mushy zone. Therefore, tendency of freckle formation is strongly influenced by density change during solidification and dendrite arm geometry (spacing and direction). In other words, the tendency can be expressed by a combination of the chemical composition effect term and solidification conditions effect term.

In order to exterminate freckles with minimum risk and cost in remelted ingots, first of all, the critical solidification conditions, cooling rate; $V(K / s)$, solidification rate; $R(\mathrm{~m} / \mathrm{s})$, thermal gradient; $\mathrm{G}(\mathrm{K} / \mathrm{m})$, and solidification front shape for freckle formation; $\theta$ (degrees) in Alloy 718 were investigated using horizontal directional solidification (H-DS) experiments. Then, the critical value for freckle formation obtained from the H-DS experiments was evaluated by investigating commercial sized ingots. For the evaluation, an expression based on the Rayleigh criterion including solidification rate, thermal gradient, and solidification front angle to the horizontal plane was developed and applied. Finally, based on the results of the 
above trials, a solidification simulation approach that make it possible to predict solidification conditions in remelted ingots, i.e. proper operating conditions of remelting process, has been developed and demonstrated.

\section{Experimental Methodology}

\section{$\underline{\text { H-DS Experiments }}$}

The schematic diagram of the horizontal directional solidification (H-DS) furnace is presented in Figure 1. First of all, the raw materials are melted by an induction furnace. Then, the molten metal is cast into the crucible of the H-DS furnace via the tundish. Before casting, the furnace temperature is controlled at $1773 \mathrm{~K}\left(1500^{\circ} \mathrm{C}\right)$ for several hours for drying crucible. After casting alloys, the temperature and solidification direction are controlled by SiC heating elements, which are settled on three sides, and the cooling block, which is settled on the other one side. The temperature change of the molten metal is monitored by several thermocouples settled along the ingot centerline. The solidification direction has some degrees to the horizontal plane because of the imperfection of the top cover. The arrangement of the cooling block and the crucible set-up also make it possible to change solidification direction. (See Figure 2)

The experimental conditions are summarized in Figure 2. Totally 6 H-DS trials for Alloy 718 were conducted in order to identify the critical conditions for freckle formation in this alloy. To get extensive solidification rates data, the furnace temperature drop rates were controlled from -30 to $-60 \mathrm{~K}$ per hour, and the temperature rises of the cooling water after cooling were controlled from 14 to $19 \mathrm{~K}$ by changing the flux of the cooling water. To get extensive solidification directions, several arrangements of the cooling block and the crucible set-up were prepared (block variations; straight, angle, and "L" type, set-up variations; horizontal, and bending forward/backward).

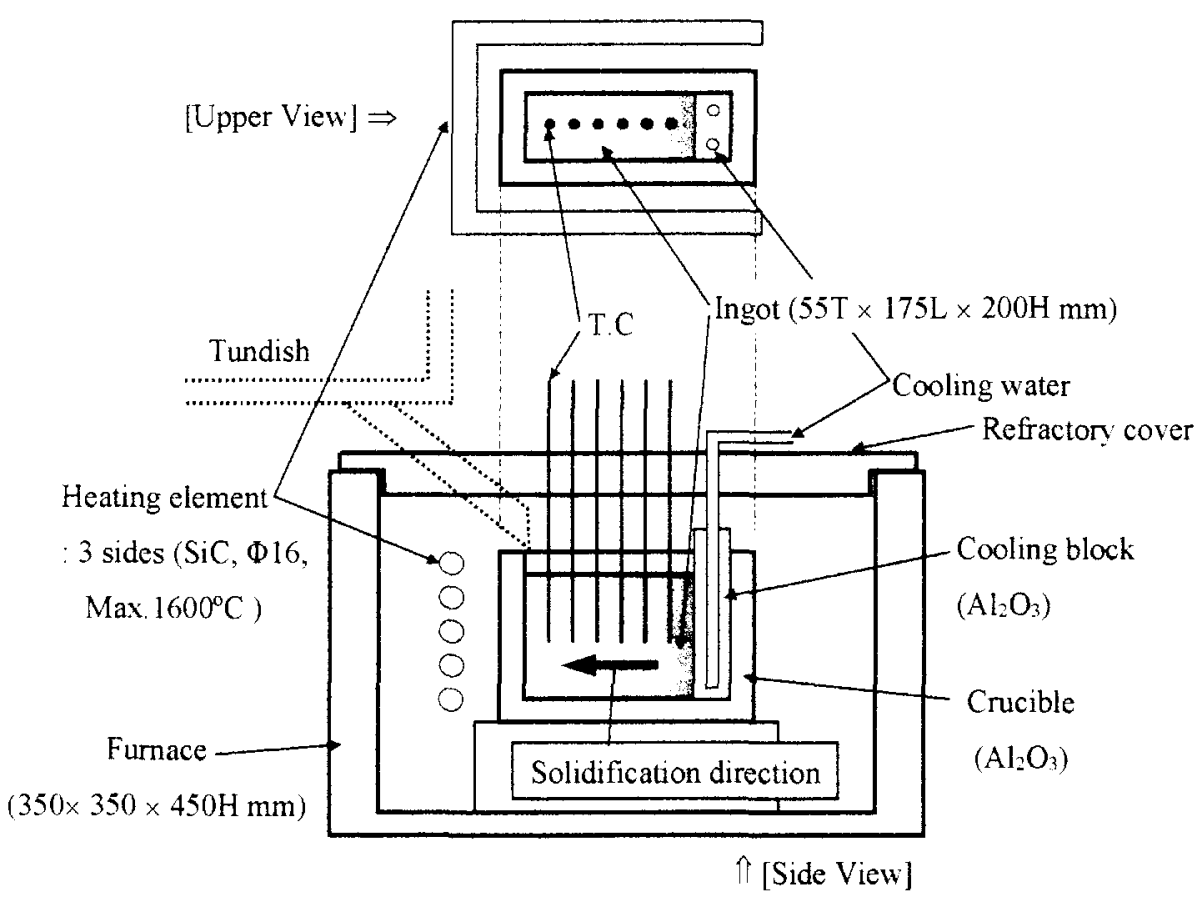

Figure 1: Schematic diagram of the horizontal directional solidification furnace. Upper view and Side view. 


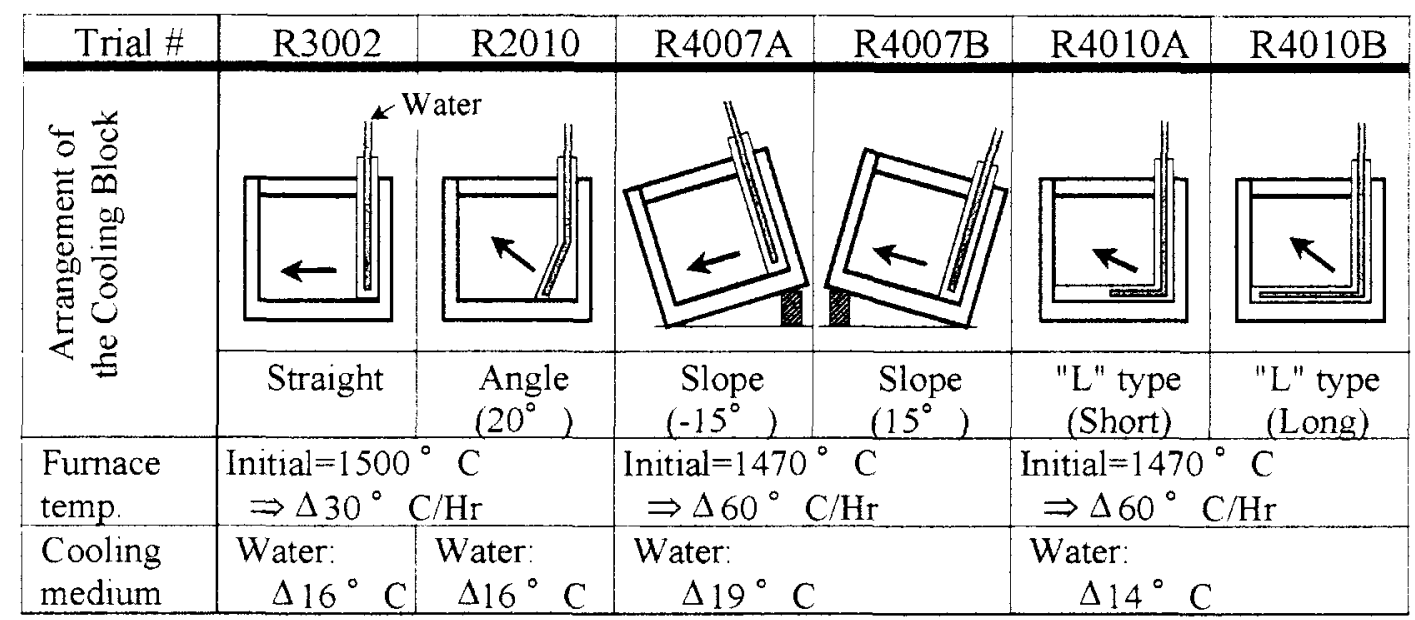

Figure 2: H-DS experimental conditions for Alloy 718. [The arrangement of the cooling block]

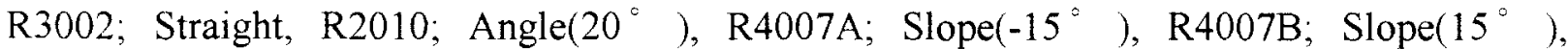
R4010A; "L" type (short), and R4010B; "L" type (long).

\section{VAR Experiments}

In VAR process, it is generally agreed that long local solidification time (LST) condition tends to generate freckles. There are three ways to lengthen the LST. First method is to keep high melt rate all over the remelting. Second is to deepen molten metal pool depth gradually by rapid increase of melt rate. Then, third is to deepen molten metal pool depth rapidly by changing arc behavior from constricted to diffuse type. Arc behavior in VAR is strongly influenced by $\mathrm{CO}$ pressure and electrode gap. Constricted arcs are stabilized by high $\mathrm{CO}$ pressures and long electrode gaps, and then molten metal would be shallow and off axis. On the other hand, diffuse arcs are stabilized by low CO pressures and short electrode gaps, and then molten metal pool would be deep and symmetrical with the axis. It is found that there is a critical point, which is a transition in fluid flow from buoyancy to Lorentz as the melting current is increase from $6.6 \mathrm{kA}$ to $7.6 \mathrm{kA}{ }^{[1]}$. In any case, freckles might be generated when the molten metal pool depth is deep enough or getting deeper. In other words, not to get any freckles in usual remelting, superalloy producers have been trying to keep low pressure, short electrode gap, and low and stable melt rate.

Figure 3 shows the plan for Alloy 718. Because of the restriction of the VAR furnace, the first and second method to lengthen LST, rapid increase of current and keeping high melt rate, were applied to generate freckles. For this experimental, it was expected that darker part in this figures, the easier freckles would occur. The electrode conditions for the experiments are also shown in Table I.

Table I: Electrode conditions for Alloy 718 VAR experiment

Item

Composition (\%)

Weight $(\mathrm{kg})$

Diameter (mm)

Mold Diameter ( $\mathrm{mm}$ )

Electrode Preparation
Alloy 718

Ni-18Cr-18Fe-3Mo-0.5Al-1 Ti-5.2Nb

1900

380

457

VIM - VAR - Forge 


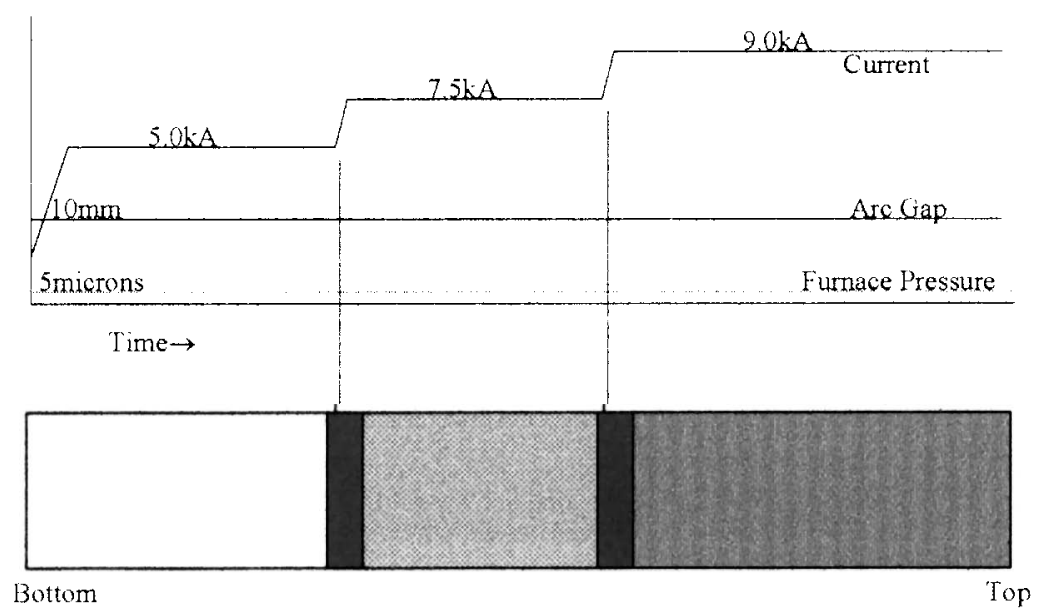

Figure 3: VAR experiments plan for Alloy 718. It was expected that darker part in this figure, the easier freckles would occur.

\section{Results and Discussion}

\section{$\underline{\text { H-DS Experiments }}$}

Temperature profiles The temperature and time data of H-DS trials are shown in Figure 4. The time in each graph is the time after casting ( $s$ ), and temperature data in each graph is molten metal's temperature $(\mathrm{K})$. In all trials, the temperature difference between near and far from the chill is seems to be big enough to get directionally solidified grains. The averaged liquidus temperatures in H-DS trials are obtained. The liquidus of Alloy 718 is $1629 \mathrm{~K}\left(1356^{\circ} \mathrm{C}\right)$.

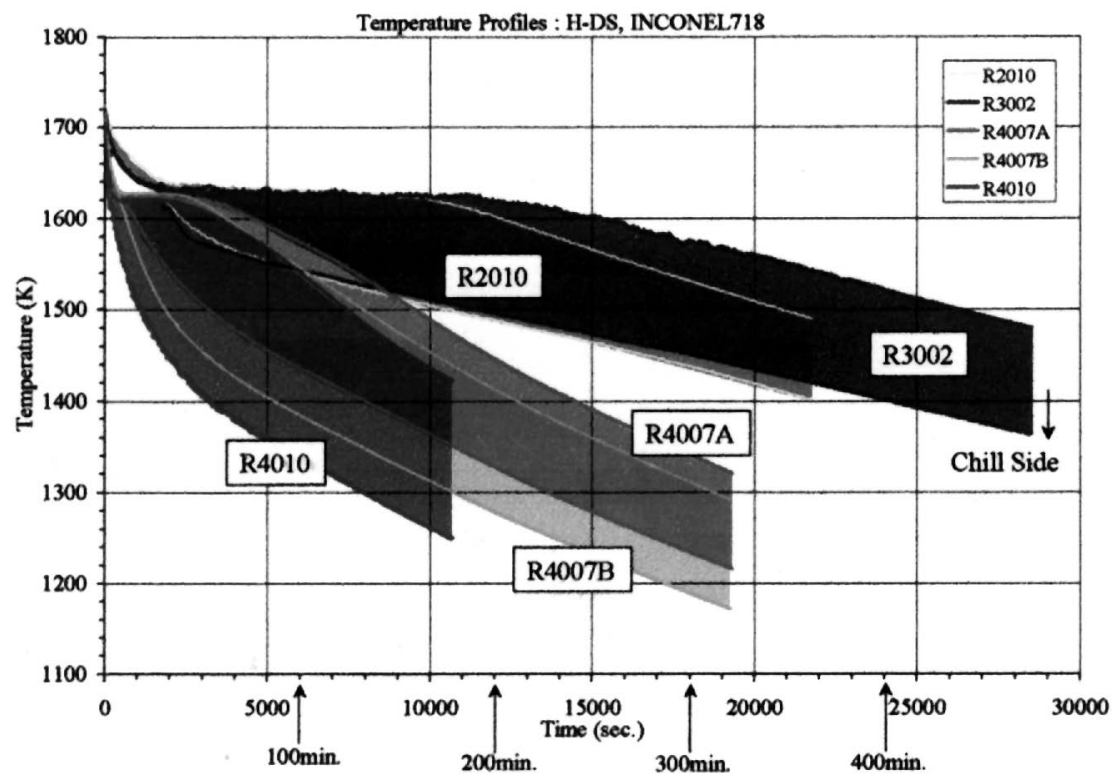

Figure 4: Temperature profiles in H-DS trials. Bottom side is the temperature data near the chill and topside is the temperature far from the chill. 
Solidification conditions In order to systematize the tendency for freckle formation, all solidification conditions at 15 Kelvin below liquidus point $\left(T_{L}-15 \mathrm{~K}\right)$ were selected for any calculation in this study, because $T_{L}-15 \mathrm{~K}$ can be considered as freckle's initiation temperature ${ }^{[2 .}$ ${ }^{3]}$. The cooling rates $(\mathrm{V}, \mathrm{K} / \mathrm{s})$ at $\mathrm{T}_{\mathrm{L}}-15 \mathrm{~K}$ obtained from temperature data are shown in Figure 5 . In all ingot, it is clear that the nearer the chill, the higher $\mathrm{V}$ before $0.07 \mathrm{~m}$ from the chill, however, it is not so clear after $0.07 \mathrm{~m}$ in most of the cases. It is because cooling effect of the chill was small at far from the chill, and there might be some cooling effect from the other side. It is found that $\mathrm{V}$ at $\mathrm{T}_{\mathrm{L}}-15 \mathrm{~K}$ can be controlled from $0.01 \mathrm{~K} / \mathrm{s}\left(0.6^{\circ} \mathrm{C} / \mathrm{min}\right)$ up to $0.1 \mathrm{~K} / \mathrm{s}\left(6^{\circ}\right.$ $\mathrm{C} / \mathrm{min}$ ). The correlation between $\mathrm{R}$ and $\mathrm{G}$ is shown in Figure 6 . The absence and existence of freckles are divided by broken line. In the case of Alloy 718 at $T_{\mathrm{L}}-15 \mathrm{~K}$, it can be described as the equation, $G=\left(6.0 \times 10^{-4}\right) / R$. It is found that $R$ at $T_{L}-15 \mathrm{~K}$ can be controlled from $0.8^{*} 10^{-5} \mathrm{~m} / \mathrm{s}$ $(0.5 \mathrm{~mm} / \mathrm{min})$ up to $5.0 \times 10^{-5} \mathrm{~m} / \mathrm{s}(3.0 \mathrm{~mm} / \mathrm{min})$, and $\mathrm{G}$ at $\mathrm{T}_{\mathrm{L}}-15 \mathrm{~K}$ can be controlled up to 8000 $\mathrm{K} / \mathrm{m}\left(8^{\circ} \mathrm{C} / \mathrm{mm}\right)$. Because $\mathrm{R}$ and $\mathrm{G}$ in the typical industrial conditions are $1.4 \times 10^{-5}$ to $5.5 \times 10^{-5}$ $\mathrm{m} / \mathrm{s}$ (from 0.8 to $3.3 \mathrm{~mm} / \mathrm{min}$ ), and 500 to $4000 \mathrm{~K} / \mathrm{m}$ (from 0.5 to $4^{\circ} \mathrm{C} / \mathrm{mm}$ ), most of all industrial $\mathrm{R}$ and $\mathrm{G}$ region can be covered by $\mathrm{H}$-DS trial.

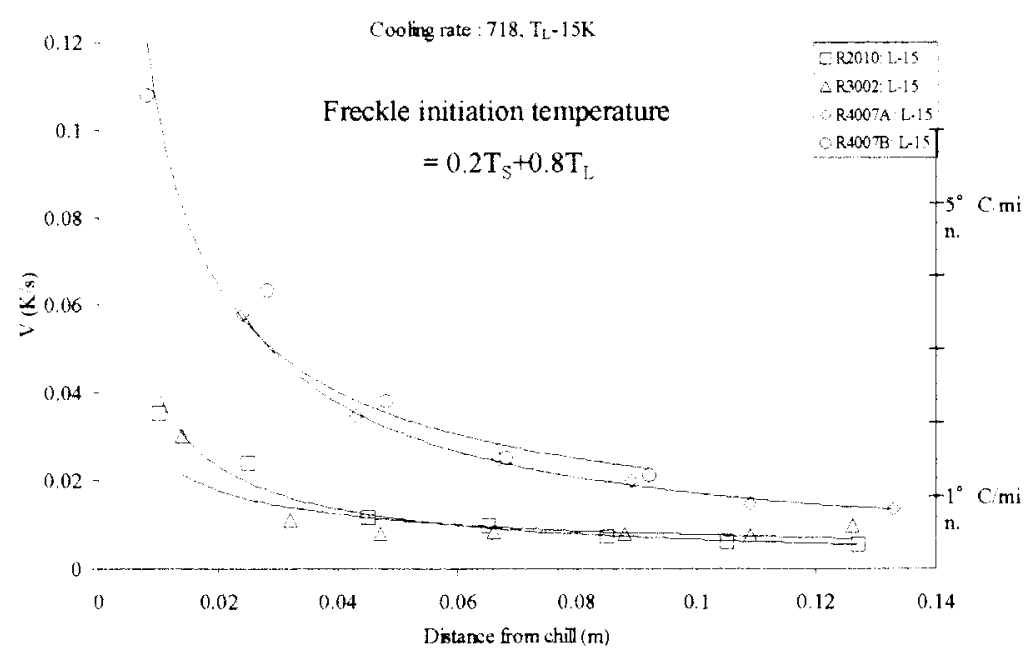

Figure 5: Cooling rate in H-DS trials

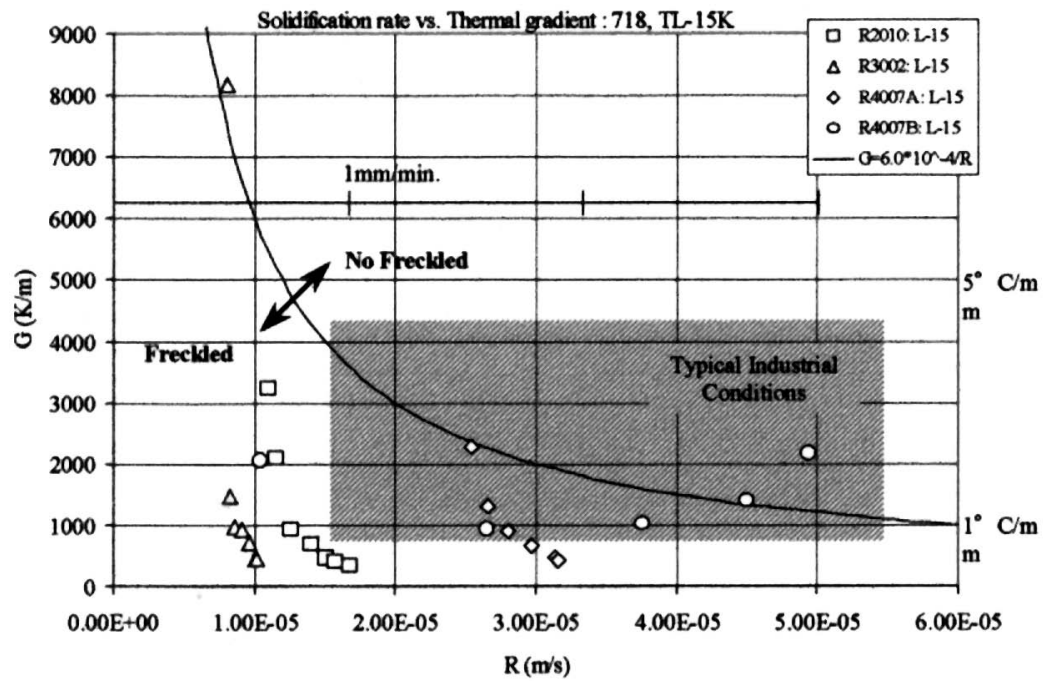

Figure 6: Solidification rate vs. Thermal Gradient in H-DS trials 
Macrostructure The example of macrostructure photographs and tracing of longitudinal and transverse cross sections of H-DS ingots is shown in Figure 7 (a), (b) and (c). In the tracing of the longitudinal cross section, the gravity direction is downward, broken lines indicate the grain direction, and solid lines with shadow indicate freckles on the surface. In the transverse cross section, dots indicate freckles. The chill surface is indicated by "chill" in both tracings and solidification always grew toward the other side. The columnar grain angles is about 33 in this case. There are several freckles in the ingot. All freckles have sharp boundaries at the chill side, and diffused boundaries at the other side. The biggest width of them is about $7 \mathrm{~mm}$. The width in lower part is wider and clearer than that in upper part. It is because the freckles in 718 are enriched in heavier elements and grow downward. The columnar grain angles are various from $14^{\circ}$ to $57^{\circ}$. To control grain direction, the sloped the mold set-up (like R4007A and B) was very effective method. The angle chill set-up (like R2010) didn't have so big effect for controlling grain angles as the sloping. The directional columnar grains weren't obtained with the "L" type chill surface (R4010A and B: rejected for investigation). Table II is the summary of the solidification conditions and the number of freckles in H-DS trials. Data of $\mathrm{V}(\mathrm{K} / \mathrm{s}), \mathrm{R}$ $(\mathrm{m} / \mathrm{s}), \mathrm{G}(\mathrm{K} / \mathrm{m})$, grain angle to the horizontal plane $(\theta$, degree), and the number of freckles $\left(1 / \mathrm{cm}^{2}\right)$ are included in the table. If the values of lower $\mathrm{V}$ were similar, the smaller $\theta$, the more likely freckles would be generated (comparison between R2010 and R3002).

Table II: Summary of the solidification conditions and the number of freckles in H-DS ingots

$\begin{array}{cccccc}\text { Trial \# } & \mathrm{V}, \times 10^{-2} \mathrm{~K} / \mathrm{s} & \mathrm{R}, \times 10^{-5} \mathrm{~m} / \mathrm{s} & \mathrm{G}, \times 10^{3} \mathrm{~K} / \mathrm{m} & \theta, & \text { Freckles, } 1 / \mathrm{cm}^{2} \\ \mathrm{R} 2010 & 0.5-3.5 & 1.1-1.7 & 0.3-3.2 & 42.0 & 0.441 \\ \mathrm{R} 3002 & 0.4-6.6 & 0.8-1.0 & 0.4-8.2 & 33.0 & 0.538 \\ \text { R4007A } & 1.3-5.8 & 2.5-3.2 & 0.4-2.3 & 14.0 & 0.131 \\ \text { R4007B } & 2.1-10.7 & 1.0-4.9 & 0.9-2.2 & 57.0 & 0.031\end{array}$

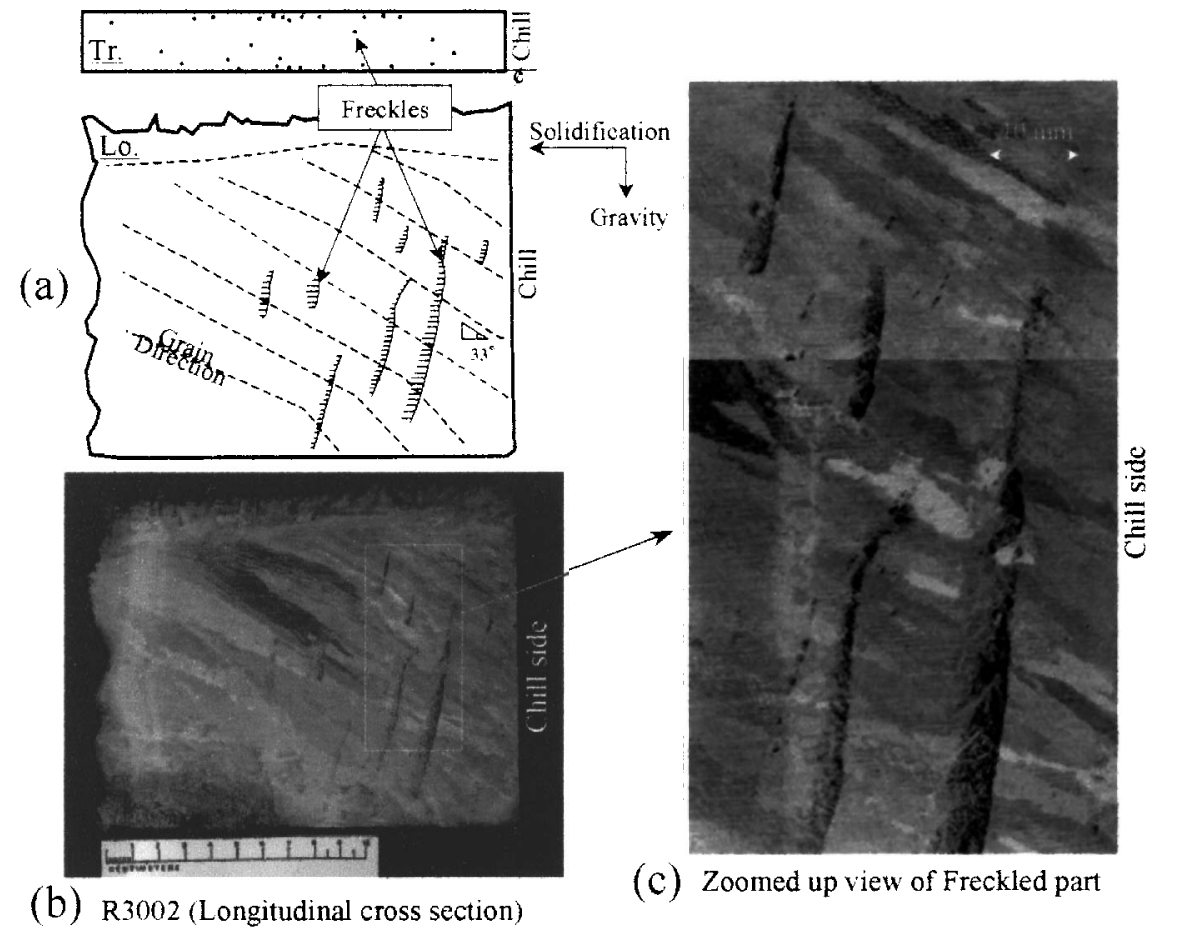

Figure 7: Macrostructure R3002, Alloy $718 \mathrm{H}-\mathrm{DS}$ ingot, (a) Tracing of macrostructure, (b) Macrostructure photographs of R3002 (longitudinal), (c) Zoomed up view of freckled part 
Microstructure: Secondary Dendrite Arm Spacing (SDAS) SDAS in H-DS ingots had been measured by counting the number of secondary dendrite arm in specific distance in the microphotographs (magnifications: 20). Tow views of photos were taken in each metallography sample, and secondary dendrite arms in three different locations were counted and spacing was averaged. Figure 8 shows the SDAS in each H-DS ingot. As far as $0.1 \mathrm{~m}$ from the chill, SDAS increase with distance from the chill in all ingots. Because of the same reason of the $V$ results, some cooling effect from the other side would have influenced the microstructure and SDAS after $0.1 \mathrm{~m}$ from the chill tend to decrease with distance. Figure 9 shows the relationship between $\mathrm{V}$ and SDAS in Alloy 718. It was found in the literature that the $\mathrm{V}$ and SDAS had a correlation that can be expressed as $\mathrm{SDAS}=\mathrm{A}^{*} \mathrm{~V}^{-\mathrm{B}}[4]$, where, $\mathrm{A}$ and $\mathrm{B}$ are constant. Then, equation (1) was obtained from Figure 8.

$$
\mathrm{SDAS}=6.93 \times 10^{-5} \times \mathrm{V}_{\mathrm{TL}-15 \mathrm{~K}}^{-0.2425}\left(\mathrm{R}^{2}=0.77\right)
$$

Where, $V_{T L-15 \mathrm{~K}}$ is the cooling rate at $T_{L}-15 \mathrm{~K}$. SDAS is in meters, and each $\mathrm{V}$ is in Kelvin per second. This equation will be used for the calculation to obtain the solidification conditions from microstructure in the VAR ingot.

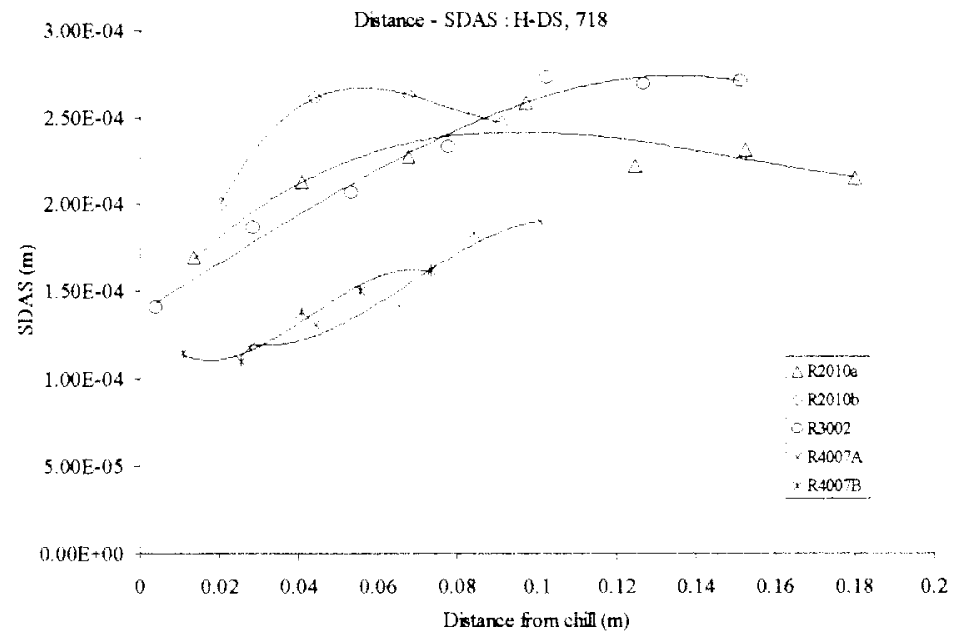

Figure 8: SDAS in H-DS ingots

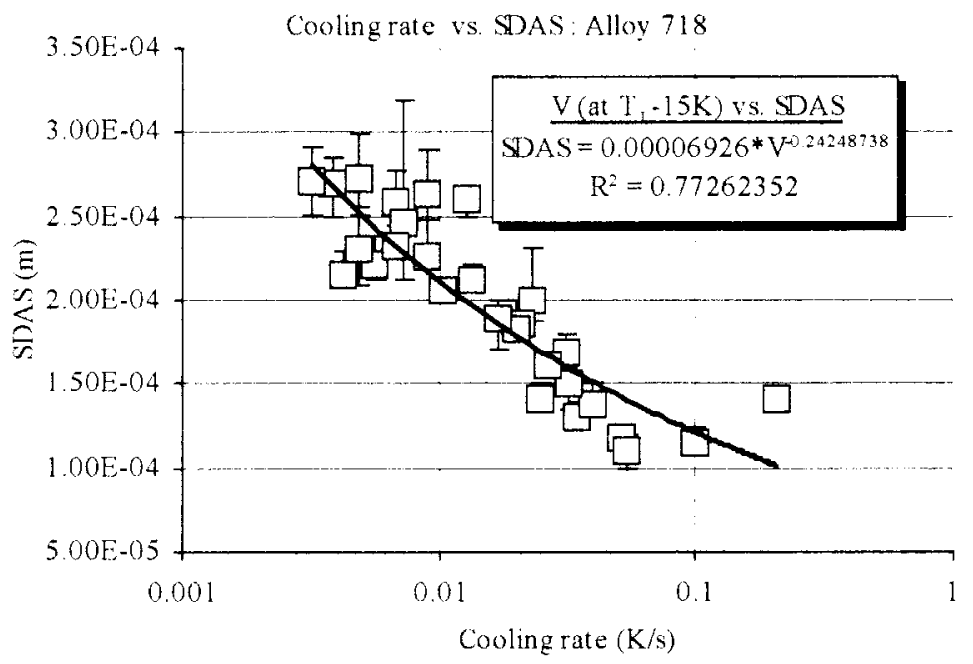

Figure 9: Cooling rate vs. SDAS 
Macrostructure The results of macrostructure of VAR ingot are summarized in Table III. The tracing of longitudinal cross sections of VAR Alloy 718 ingot is shown in Figure 10 with the remelting chart. The samples were cut from the ingot along the centerline. Uni-directional grains had been obtained overall the ingot, and there are some pipes on the top part because of the operating conditions without hot topping. Some freckles had been generated around the part that current had been changed from 7.5 to $9.0 \mathrm{kA}$ in the middle-1 (M1) sample. The freckles are mostly located between mid-radius and edge of the ingot. The change to higher current should have caused some melt back into a region of ingot created under lower current conditions. Grain angles to the horizontal plane had been getting smaller with current increasing. Figure 11 shows the longitudinal cross sections of M1. Clear freckle lines are found in this region. Freckles in the ingot has almost right angle to the columnar grains. M1 and M2 were cut into every $50 \mathrm{~mm}$ for observing the transverse cross sections. Freckles on the transverse cross sections were found only in M1. In the transverse cross section of M1, totally 6 freckles were found in this region. They started at $10 \mathrm{~mm}$ and ended at $140 \mathrm{~mm}$ from the ingot surface.

Table III: Summary of macrostructure in VAR 718 ingot

$\begin{array}{cccc}\text { Location, mm } & \text { Current, kA } & \text { Pool depth, mm } & \text { Freckles, YN } \\ 1100-1490 & 9.0 & - & \mathrm{N} \\ 800-1090 & 7.5-9.0 & 202-220 & \mathrm{Y} \\ 400-790 & 5.0-7.5 & 130-182 & \mathrm{~N} \\ 0-390 & 5.0 & 52-104 & \mathrm{~N}\end{array}$

[Note] Location: the sample location from the bottom of the ingot

Freckles: $\mathrm{Y}$ indicates existence of freckles, $\mathrm{N}$ indicates absence of freckles

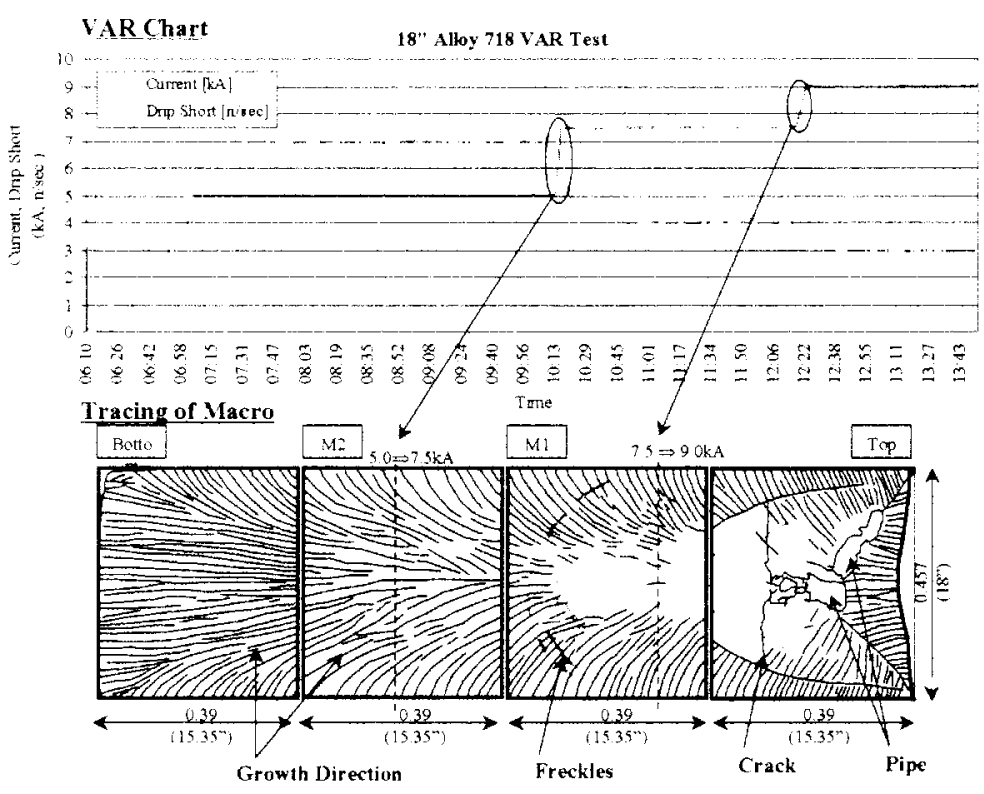

Figure 10: Tracing of longitudinal cross sections, 18 " Alloy 718 VAR ingot

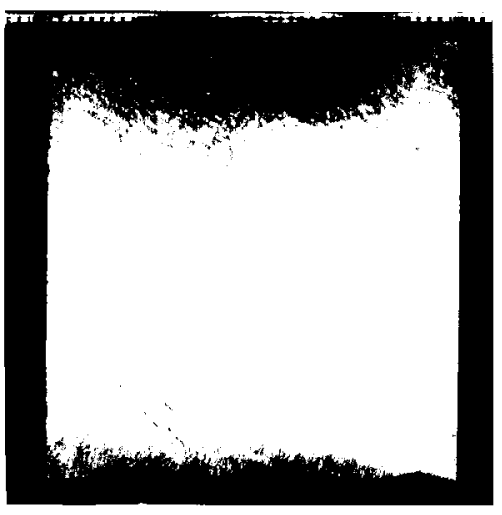

Figure 11: Macrostructure of M1 part

Microstructure: SDAS SDAS in VAR ingots were measured in same method to H-DS ingot investigation. Figure 12 shows the data of SDAS at each location in VAR ingots. The circles 
indicate that freckles are found there. Equation (1) was applied to calculate cooling rate in $\mathrm{VAR}$ ingot, and Figure 13 shows the $\mathrm{V}$ at $\mathrm{T}_{\mathrm{l}}-15 \mathrm{~K}$. In this graph, the circles indicate freckled parts, too. The tendency for freckle formation is not found in these figures.

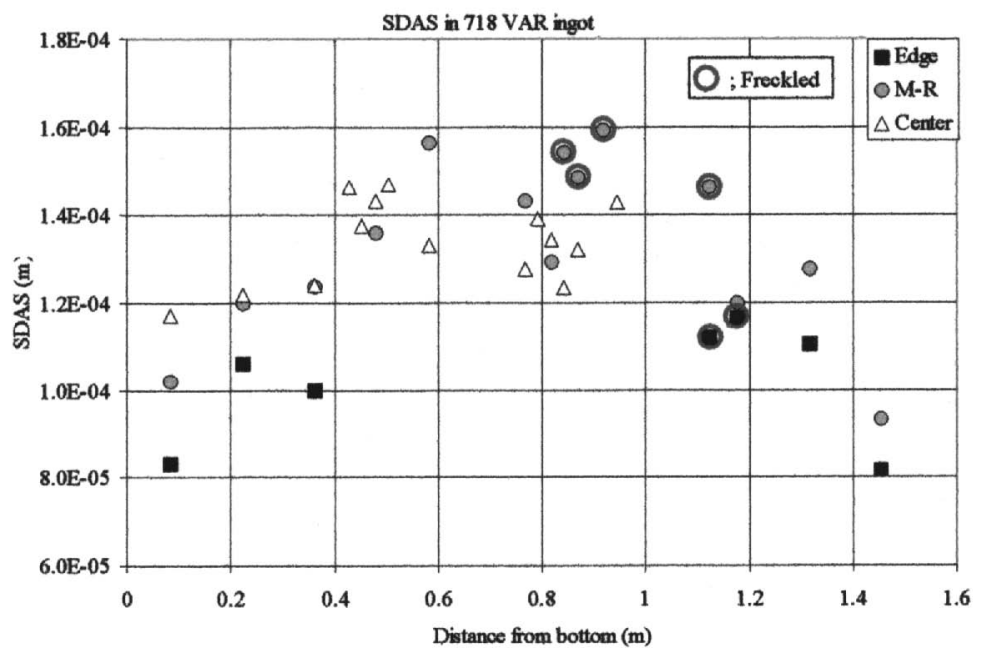

Figure 12: SDAS in VAR ingot, Circles indicate freckles were found at those parts

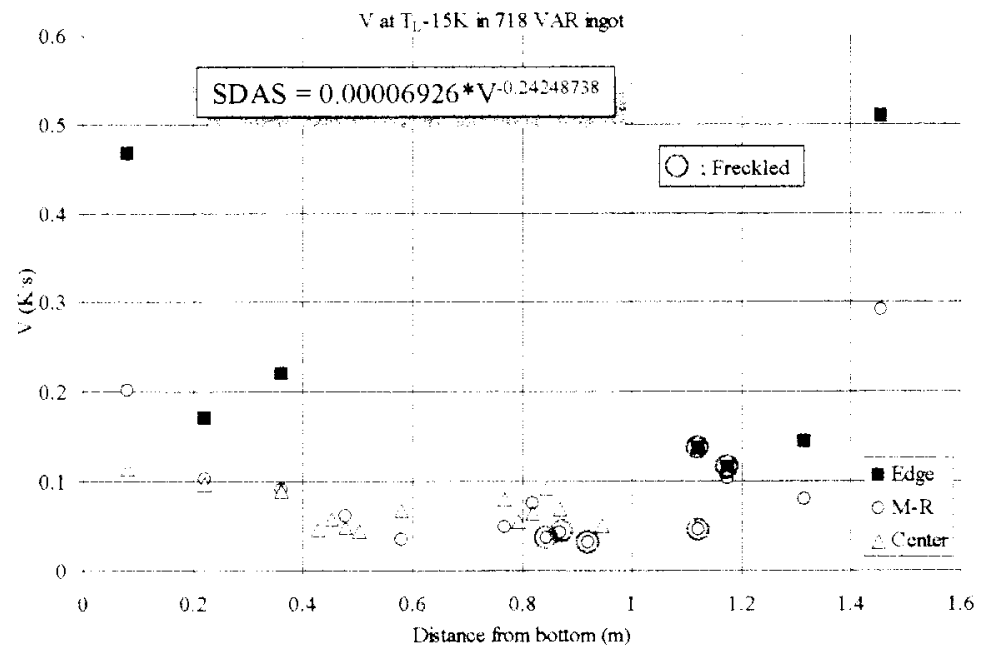

Figure 13: Calculated V in VAR ingot, Circles indicate freckles were found at those parts

\section{Application of Rayleigh Criterion}

Modifying Rayleigh Criterion Many freckling criteria have been proposed in literatures. In this study, a criteria based on the Rayleigh Number was applied for estimating the tendency for freckle formation. One of the forms of Rayleigh number had been given in equation (2) ${ }^{|5|}$.

$$
\mathrm{Ra}=\frac{\mathrm{g} \frac{\mathrm{d} \rho}{\mathrm{dz}}}{\frac{\eta \mathrm{D}_{\mathrm{I}}}{\mathrm{h}^{4}}}
$$

Where, Ra is a Rayleigh number $(-)$. g, $\mathrm{d} \rho / \mathrm{dz}, \mathrm{h}, \mathrm{DT}$, and h are gravitational constant $\left(\mathrm{m} / \mathrm{s}^{2}\right)$, density inversion term in vertical direction $\left(\mathrm{kg} / \mathrm{m}^{4}\right)$, dynamic viscosity $(\mathrm{kg} / \mathrm{ms})$, thermal diffusivity $\left(\mathrm{m}^{2} / \mathrm{s}\right)$, and characteristic length $(\mathrm{m})$, respectively. In this criterion, characteristic 
length $\mathrm{h}$ has been considered as primary dendrite arm spacing (PDAS, $\mathrm{m}$ ), and PDAS can be estimated from $\mathrm{G}$ and $\mathrm{R}$ as following ${ }^{[6]}$.

$$
\mathrm{PDAS}=\mathrm{K} \times \mathrm{G}^{-1 / 2} \times \mathrm{R}^{-1 / 4}
$$

Where, $\mathrm{K}$ is constant in particular alloy. The remaining terms, $\mathrm{g}, \mathrm{d} \rho / \mathrm{dz}, \mathrm{h}$, and DT have been given in equation (4), (5), (6), and (7) ${ }^{[7]}$.

$$
\begin{gathered}
g=9.81 \\
\frac{d \rho}{d z}=\frac{d \rho}{d T} \times \frac{d T}{d z}=\frac{d \rho}{d T} \times G=30 \times G \\
\eta=0.004 \\
D_{T}=9.0 \times 10^{-6}
\end{gathered}
$$

In equation (5), $\mathrm{G}$ was originally defined as vertical thermal gradient at freckle initiation temperature, however $G$ in this case is considered as same as actual $G$ at freckle initiation temperature. Then, equation (8) was obtained from equation (2) to (7)

$$
\mathrm{Ra}=\frac{\mathrm{A}}{\mathrm{G} \times \mathrm{R}}
$$

Where, $\mathrm{A}=8.185 \times 10^{9} \times \mathrm{K}(\mathrm{s} / \mathrm{K})$. Because there is no term that considers solidification geometry, $1 / \sin \theta$ was involved into equation (8). $\theta$ is defined as the solidification front angle to the horizontal plane. Then, finally, the relative Rayleigh number $\left(\mathrm{Ra}^{*}\right)$ was obtained as equation (9).

$$
\mathrm{Ra}^{*}=\frac{\mathrm{A}}{\mathrm{G} \times \mathrm{R} \times \sin \theta}
$$

Application for H-DS ingots The results of application of $\mathrm{Ra}^{*}$ for $\mathrm{H}$-DS ingots are shown in Figure 14. $\mathrm{Ra}^{*}$ data of any ingots increase with distance from the chill. $\mathrm{Ra}^{*}$ has a clear critical value for freckle formation. Although there are few data under critical value, there is no exception. The critical value for freckle formation is about 25 . The results of Ra* application for H-DS ingots are summarized in Table IV with the results for VAR ingots.

Application for VAR ingots The results of application of $\mathrm{Ra}^{*}$ for VAR ingots are shown in Figure 15. $\mathrm{Ra}^{*}$ in $718 \mathrm{VAR}$ ingot has a boundary which divide the freckle existence and absence. There are two exceptions, but there might be freckles near the exceptions because these are the part the current had been risen or stopped so that there had been unstable conditions around there. The critical value for freckle formation obtained in H-DS results (Figure 14) has also good agreement with it. The correlation between melt rate and $\mathrm{Ra}^{*}$ is also shown in Figure 16

Table IV: Summary of the application of relative Rayleigh number for Alloy 718

\begin{tabular}{cccc}
\multicolumn{2}{c}{ H-DS ingots } & \multicolumn{2}{c}{ VAR ingot } \\
Exceptions/Data & Critical value & Exceptions/Data & Critical value \\
$0 / 28$ & 25 & $2 / 35$ & 25
\end{tabular}




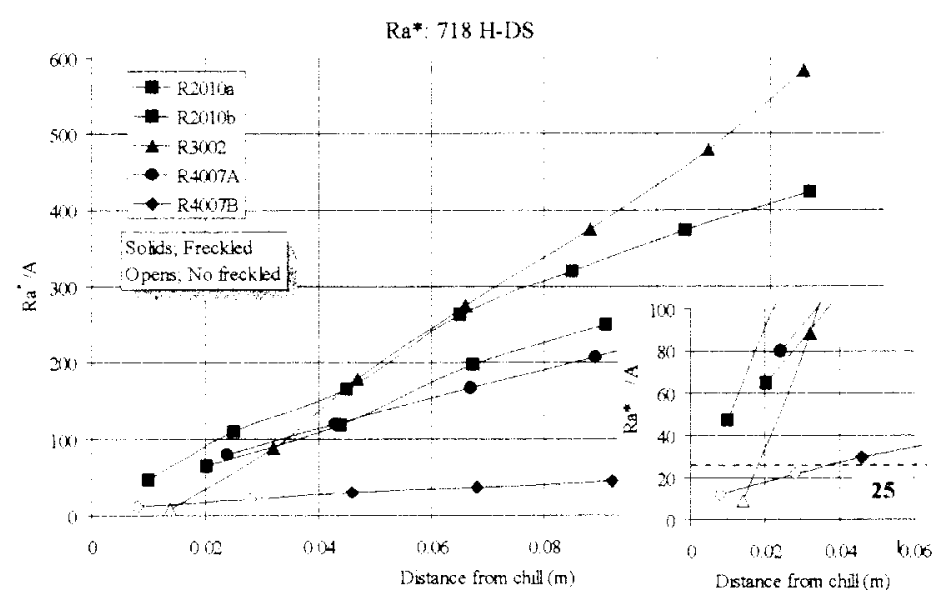

Figure 14: Relative Rayleigh number for H-DS ingots

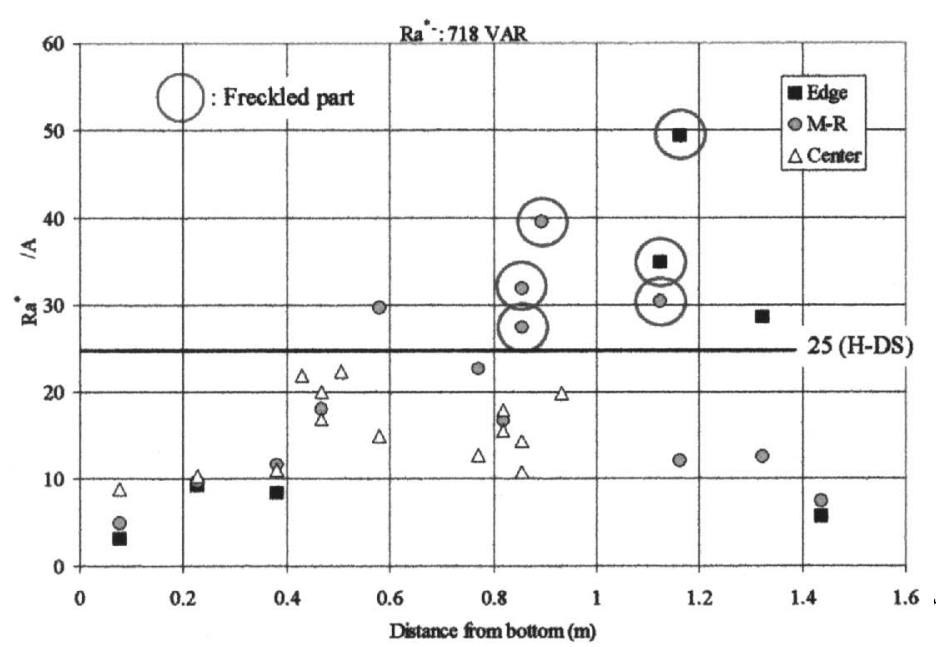

Figure 15: Relative Rayleigh number for VAR ingots

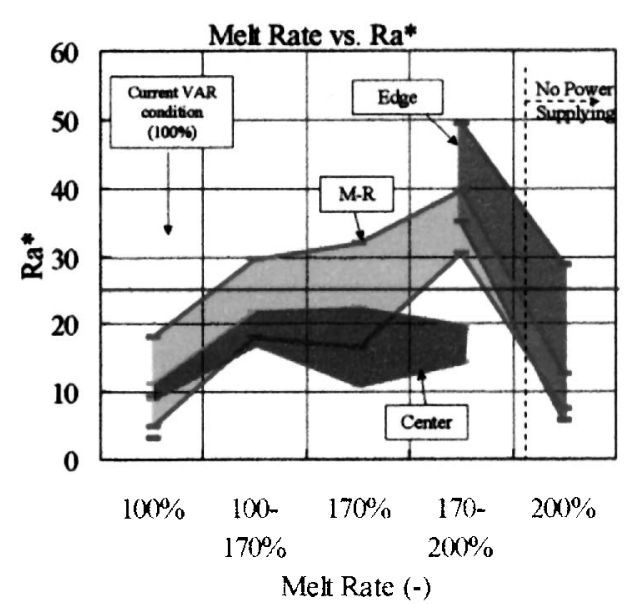

Figure 16: Melt rate vs. $\mathrm{Ra}^{*}$ in VAR ingot

\section{Solidification Simulation}

Based on the results of the H-DS and VAR trials, a solidification simulation program has been developed. Up to this time, basic calculation routine program has been completed and some calculation samples are demonstrated. The analysis technique and output data are summarized in Table V. This code has been self- made and finite differential analysis method was applied.

Table V: Summary of the analysis method and output data

$\begin{array}{lllll}\text { Model } & \text { Geometry } & \text { Analysis }(F D A) & \text { Boundary conditions } & \text { Output data } \\ \text { VAR 1/2 } & \text { Two dimension } & \text { Stream } & \text { Top: heat input, } & \text { Temperature } \\ & \text { Axis- } & \text { function }(\Phi) & \text { radiation cooling } & \text { V, G, R, } \theta \\ & \text { symmetric } & \text { Vorticity }(\omega) & \underline{\text { Side, Bottom: }} & \text { Pool shape } \\ & & \text { Temperature }(\mathrm{T}) & \text { conductive cooling } & \text { Ra* etc. }\end{array}$

Calculation example Figure 17 shows the example of $\mathrm{Ra}^{*}$ calculation in the VAR trial, and Figure 18 is the $\theta$ calculation. Regarding data at the mid-radius and center region, both $\mathrm{Ra}^{*}$ and $\theta$ in Alloy $718 \mathrm{VAR}$ ingot can be predicted. At this moment, the reason why calculation at edge doesn't have good agreement with the results of the trials hasn't been clear yet. 


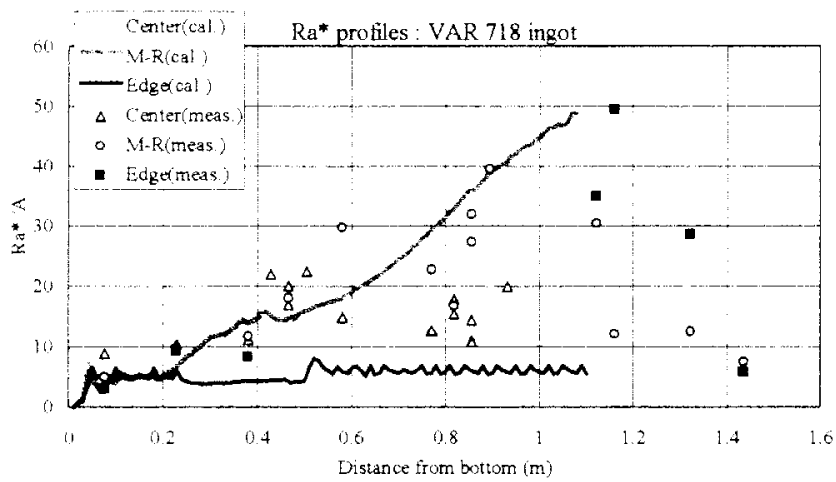

Figure 17: $\mathrm{Ra}^{*}$ calculation (example 1)

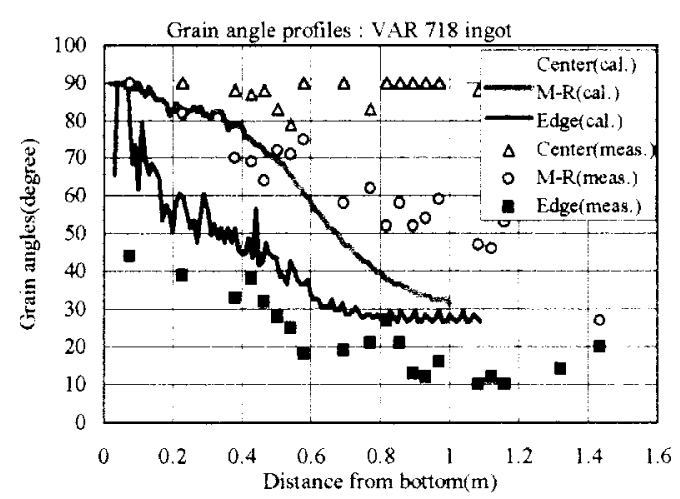

Figure 18: $\theta$ calculation (example 2)

\section{Conclusions}

1. Freckles were generated in H-DS and commercial-sized Alloy 718 VAR ingot under specific conditions. Freckles in VAR ingot were located mostly between mid-radius and edge. They have almost right angle to the columnar grains, which means freckle's shape was similar to the molten metal pool.

2. A relative Rayleigh number $\left(\mathrm{Ra}^{*}\right)$ has been applied for estimation of the tendency for the freckle formation in H-DS and VAR ingots. Regarding the results of application, $\mathrm{Ra}^{*}$ have clear boundaries between existence and absence of freckles. The critical value for freckle formation is about 25 .

3. However the solidification simulation program has not been completed, it's found that it would be able to predict the solidification conditions during Alloy 718 VAR process.

\section{Acknowledgement}

The authors would like to thank Dr. Shailesh Patel for his endeavor for organizing this joint research work. Constructive discussions and theoretical guidance from Dr. Frank J. Zanner, Dr. Keh-Minn Chang, and Dr. Jack deBarbadillo are greatly appreciated. Special thanks are due to Dr. Norioki Uehara for his helpful guidance for pushing this research forward.

\section{References}

1. F. J. Zanner et al., "Relationship between $520 \mathrm{~mm}$ Diameter INCONEL 718 Alloy Ingot Pool Profiles and Vacuum Arc Remelt Operational Parameters", Special Melting and Processing Technologies, pp.551-563, Proceeding of the Ninth International Vacuum Conference on Special Melting, San Diego, Calif., April 11-15, 1988.

2. P. Auburtin et al., "Freckle Formation and Freckle Criterion in Superalloy Casting", Metall. Trans. B, 2000, vol. 31B.

3. W. Yang et al., "Segregation and Solid Evolution During the Solidification of NiobiumContaining Superalloys", Superalloys 2000, pp.75-84, Proceedings of Superalloys 2000, TMS, Seven Springs, PA, Sep. 2000.TMS

4. T. Bower et al., Trans. Met. Soc. AIME, 236, 1966.

5. J. Sarazin and A. Hellawell, Metall. Trans. A, 1988, vol. 19A.

6. J. Hunt, "Keynote Address: Cellular and Primary Dendrite Spacings", Solidification and Casting Metals, vol. 192, The Metal Society, London.

7. P. Auburtin, "Determination of the Influence of Growth Angle on Freckle Formation in Superalloys", Ph.D. Thesis, University of British Columbia, Vancouver, BC, Canada, 1998. 